Umberto Lucangelo

Agostino Accardo

Alessandro Bernardi

Massimo Ferluga

Massimo Borelli

Vittorio Antonaglia

Fabio Riscica

Walter A. Zin

\section{Gas distribution in a two-compartment model ventilated in high-frequency percussive and pressure-controlled modes}

Received: 11 June 2009

Accepted: 9 June 2010

Published online: 6 August 2010

(C) Copyright jointly held by Springer and ESICM 2010

Electronic supplementary material

The online version of this article (doi:10.1007/s00134-010-1993-3) contains supplementary material, which is available to authorized users.

U. Lucangelo (®) · M. Ferluga .

V. Antonaglia

Department of Perioperative Medicine, Intensive Care and Emergency, Cattinara Hospital, Trieste University

School of Medicine, Strada di Fiume 447, 34139 Trieste, Italy

e-mail: u.lucangelo@fmc.units.it

Tel.: +39-040-3994540

Fax: +39-040-912278

A. Accardo - A. Bernardi - F. Riscica Department of Electrotechnics,

Electronics and Computer Science,

Trieste University, Trieste, Italy

M. Borelli

B.R.A.I.N. Centre for Neuroscience,

Trieste University, Trieste, Italy

W. A. Zin

Carlos Chagas Filho Institute of Biophysics, Federal University of Rio de Janeiro,

Rio de Janeiro, Brazil
Abstract Purpose: To demonstrate in a two-compartment heterogeneous mechanical model of the lung how different loads applied to one compartment, while the other is kept constant, would modify gas distribution between the two pathways under high-frequency percussive ventilation (HFPV).

Additionally, these results were compared with those generated in the same model by pressure-controlled ventilation (PCV). Methods: Analysis was based on a Siemens lung simulator, representing a fixed branch of the system with an elastance equal to $45 \mathrm{cmH}_{2} \mathrm{O} / \mathrm{L}$ and a resistance of $20 \mathrm{cmH}_{2} \mathrm{O} / \mathrm{L} / \mathrm{s}$, and a single-compartment lung simulator, representing a variable pathway of the model, presenting three elastic loads varying between 35 and $85 \mathrm{cmH}_{2} \mathrm{O} / \mathrm{L}$ and three resistive loads varying between 5 and $50 \mathrm{cmH}_{2} \mathrm{O} / \mathrm{L} / \mathrm{s}$. Each simulator represented one compartment of the model connected to a central airway that was ventilated with either a volumetric diffusive respirator (VDR-4; Percussionaire Corporation, Sandpoint, ID, USA) or a Siemens Servo 900c ventilator. Flow and pressures were measured in each branch of the model under nine conditions representing the combinations of three elastic and three resistive loads (variable branch) while the loads in the other pathway were kept constant. Results: HFPV was able to avoid hyperinflation and reduce tidal volume in a bicompartmental heterogeneous lung model. Under HFPV, gas distribution between the two compartments was not constrained by their time constants. PCV yielded gas distribution as determined by the time constant of each compartment. Conclusions: HFPV accommodated volume distribution without overinflating compartments with low time constants, thus possibly presenting a potential protective behavior in mechanically heterogeneous lungs.

Keywords High-frequency percussive ventilation .

Pressure-controlled ventilation . Time constant - Two-compartment model · Volume distribution . Loading

\section{Introduction}

High-frequency percussive ventilation (HFPV) combines the beneficial aspects of conventional mechanical ventilation with those of high-frequency ventilation [1]. It has been used in some conditions in both adults [2-9] and children [10, 11]. Furthermore, it has been proved effective when conventional 
mechanical ventilation might impair other organ functions [12-18].

Recently a one-compartment linear model of the respiratory system has been successfully used to demonstrate the effects of mechanical resistive and elastic loading on flow, tidal volume, and pressure curves generated by HFPV as well as on the resulting washout of gas from the lungs $[19,20]$. However, the consequences of HFPV on a mechanically heterogeneous lung have yet to be explored. It should be stressed that the effects of HFPV in a heterogeneous system are complex, since not only the mechanical interactions play an important role in the determination of gas distribution, but also the system delivering HFPV modulates tidal volume delivery in accordance with the imposed mechanical loads.

In this study we aim to investigate in a two-compartment heterogeneous mechanical model of the lung whether different mechanical resistive and elastic loads applied to one compartment, while the other is kept constant, would modify gas distribution between the two pathways and air trapping under HFPV. Additionally, these results were compared with those generated in the same model by pressure-controlled ventilation (PCV).

\section{Materials and methods}

We based our study on the two-compartment parallel model introduced by Otis et al. [21], extending our previous studies $[19,20]$. In such a model the distribution of the overall flow in the separate branches depends on the impedances of each independent compartment. Under spontaneous or conventional mechanical ventilation, if the elastance $(E)$ and resistance $(R)$ of each pathway are identical in both branches, there will be no difference in the volume flowing into each one. However, if the separate compartments present different time constants $(\tau=R / E)$, they will fill up according to their time constants, i.e., a shorter time constant will allow a larger volume into the corresponding compartment. The parameters of the fixed compartment were kept constant throughout the experiment $\left(E_{\mathrm{F}}=45 \mathrm{cmH}_{2} \mathrm{O} / \mathrm{L}\right.$ and $\left.R_{\mathrm{F}}=20 \mathrm{cmH}_{2} \mathrm{O} / \mathrm{L} / \mathrm{s}\right)$ and were generated by a Siemens lung simulator (Siemens Test Lung 190; Siemens AG, Munich, Germany), while the variable one was provided by a single-compartment lung simulator (Medishield, Harlow Essex, UK) characterized by three elastic loads $\left(E_{\mathrm{V}}=35,55\right.$, and $\left.85 \mathrm{cmH}_{2} \mathrm{O} / \mathrm{L}\right)$ and three resistive loads $\left(R_{\mathrm{V}}=5,20\right.$, and $\left.50 \mathrm{cmH}_{2} \mathrm{O} / \mathrm{L} / \mathrm{s}\right)$. As a result, nine different combinations were randomly tested.

Ventilation of the mechanical model was provided by two different equipments: (1) HFPV was generated by a volumetric diffusive respirator (VDR-4; Percussionaire Corporation, Sandpoint, ID, USA) that delivers minibursts of respiratory gas mixtures in the proximal airways throughout the breath $[19,20]$. For the present purposes they were restricted to inspiration, 300 cycles/ min, and pulse inspiratory/expiratory duration ratio of $1: 1$, whereas breathing frequency amounted to 12 breaths $/ \mathrm{min}$, and inspiratory and expiratory duration $\left(T_{\mathrm{I}}\right.$ and $\left.T_{\mathrm{E}}\right)$ ratio was 1:1 [21], reaching a tele-inspiratory peak pressure of $24 \mathrm{cmH}_{2} \mathrm{O}$. (2) PCV was delivered by a Siemens Servo $900 \mathrm{c}$ ventilator (Siemens, Solna, Sweden) with the following parameters: $12 \mathrm{bpm}, I / E=1$, and peak pressure $=24 \mathrm{cmH}_{2} \mathrm{O}$. Under these settings, both ventilators produced the same peak pressure, respiratory rate, and $I / E$ ratio. No positive end-expiratory pressure (PEEP) was used in the experiments.

Model description and statistical analysis [22] are depicted in ESM 1.

Definition of total cumulative pulsatile volume $\left(V_{\mathrm{TOT}}\right)$, mean pressure $\left(\mathrm{Paw}_{\mathrm{m}}\right)$, trapped air volume (TAV), effective elastance $\left(E_{\mathrm{E}}\right)$, and effective resistance $\left(R_{\mathrm{E}}\right)$ are indicated in ESM 2.

\section{Results}

Comparing both ventilatory modes, it follows that, for the same loading, $\mathrm{PCV}$ generates higher total tidal volume $\left(V_{\mathrm{T}}\right)$ than HFPV (Tables 1,2$)(P=0.004)$. This was due to the larger volume directed to the fixed compartment during PCV $(290.8 \pm 11.7$ and $557.8 \pm 14.6 \mathrm{~mL}$, respectively; $P<0.001$ ), since there was no difference between the fractional volume injected into the variable compartment by the two ventilatory modes $(344.1 \pm 123.8$ and $457.9 \pm 141.9 \mathrm{~mL}$, respectively; $P=0.089$ ). In this regard, no difference was found in the time constant of the variable compartment when the two methods were compared $(P=1)$. Comparing the time constants of the fixed and the variable compartments, Fisher $F$ test disclosed a difference between their variances $(P<0.001)$.

\section{Pressure-time curves}

Pressure-time curves obtained with HFPV and PCV during one breathing cycle are shown in Fig. 1. Elastic and resistive loads applied to the variable branch of the model amounted to $35 \mathrm{cmH}_{2} \mathrm{O} / \mathrm{L}$ and $50 \mathrm{cmH}_{2} \mathrm{O} / \mathrm{L} / \mathrm{s}$, respectively. Tidal volume in PCV was approximately $1.09 \mathrm{~L}$ (Table 2), whereas in HFPV it amounted to $0.68 \mathrm{~L}$ (Table 1). Note that mean pressure generated by HFPV $\left(6.9 \mathrm{cmH}_{2} \mathrm{O}\right)$ approximates $55 \%$ of that produced by PCV $\left(12.8 \mathrm{cmH}_{2} \mathrm{O}\right)$. Considering the pressure changes during inspiration alone, no difference in the relationship between mean airway pressure and inspired volume was found between the two ventilatory modalities $(P=0.62)$. 


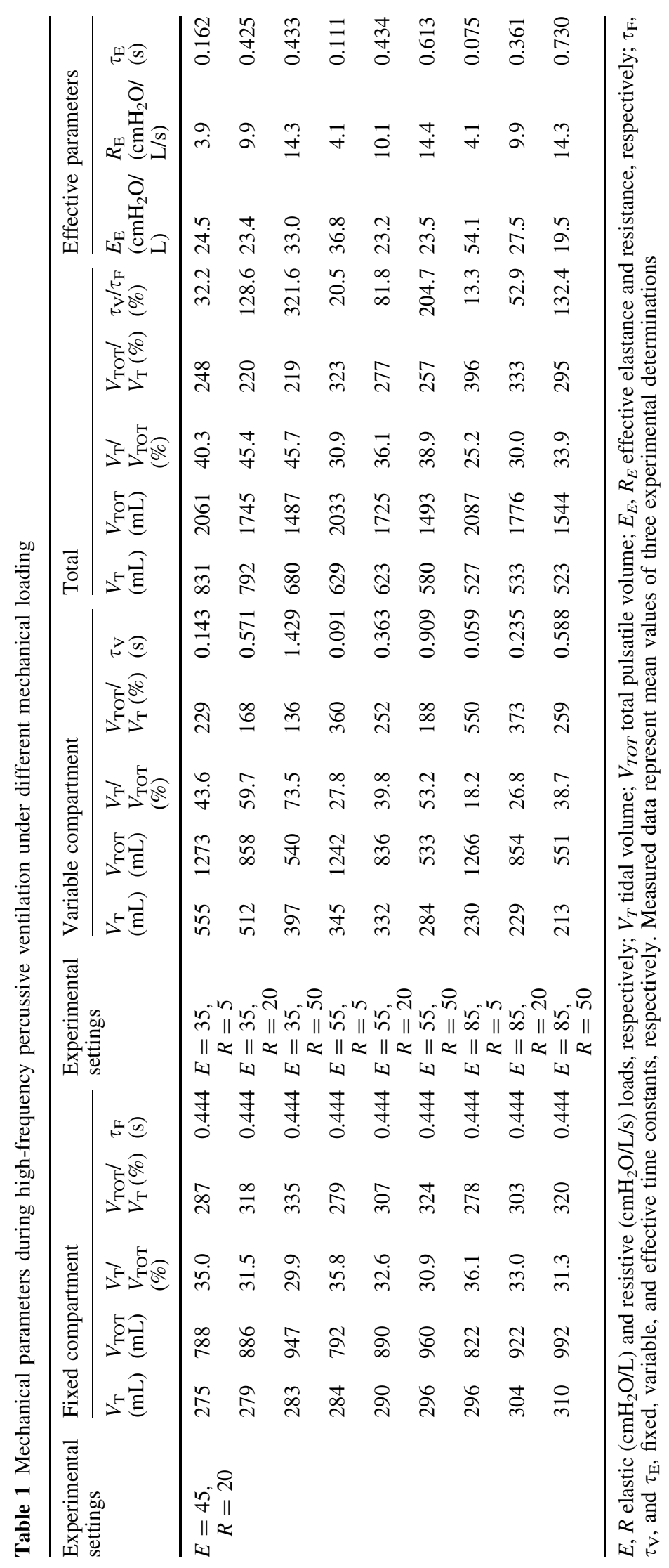


Table 2 Mechanical parameters during pressure-controlled ventilation under different mechanical loading

\begin{tabular}{|c|c|c|c|c|c|c|c|c|c|c|}
\hline \multirow[t]{2}{*}{$\begin{array}{l}\text { Experimental } \\
\text { settings }\end{array}$} & \multicolumn{2}{|c|}{$\begin{array}{l}\text { Fixed } \\
\text { compartment }\end{array}$} & \multirow[t]{2}{*}{$\begin{array}{l}\text { Experimental } \\
\text { settings }\end{array}$} & \multicolumn{2}{|c|}{$\begin{array}{l}\text { Variable } \\
\text { compartment }\end{array}$} & \multicolumn{2}{|l|}{ Total } & \multicolumn{3}{|c|}{ Effective parameters } \\
\hline & $\begin{array}{l}V_{\mathrm{T}} \\
(\mathrm{mL})\end{array}$ & $\begin{array}{l}\tau_{\mathrm{F}} \\
(\mathrm{s})\end{array}$ & & $\begin{array}{l}V_{\mathrm{T}} \\
(\mathrm{mL})\end{array}$ & $\begin{array}{l}\tau_{\mathrm{V}} \\
(\mathrm{s})\end{array}$ & $\begin{array}{l}V_{\mathrm{T}} \\
(\mathrm{mL})\end{array}$ & $\begin{array}{l}\tau_{\mathrm{V}} / \tau_{\mathrm{F}} \\
(\%)\end{array}$ & $\begin{array}{l}E_{\mathrm{E}} \\
\left(\mathrm{cmH}_{2} \mathrm{O} / \mathrm{L}\right)\end{array}$ & $\begin{array}{l}R_{\mathrm{E}} \\
\left(\mathrm{cmH}_{2} \mathrm{O} / \mathrm{L} / \mathrm{s}\right)\end{array}$ & $\begin{array}{l}\tau_{\mathrm{E}} \\
(\mathrm{s})\end{array}$ \\
\hline \multirow{9}{*}{$E=45, R=20$} & 538 & 0.444 & $E=35, R=5$ & 679 & 0.143 & 1218 & 32.2 & 20.3 & 5.1 & 0.254 \\
\hline & 541 & 0.444 & $E=35, R=20$ & 642 & 0.571 & 1184 & 128.6 & 20.7 & 10.1 & 0.486 \\
\hline & 545 & 0.444 & $E=35, R=50$ & 548 & 1.429 & 1094 & 321.6 & 26.9 & 16.7 & 0.621 \\
\hline & 556 & 0.444 & $E=55, R=5$ & 448 & 0.091 & 1004 & 20.5 & 26.1 & 6.8 & 0.262 \\
\hline & 557 & 0.444 & $E=55, R=20$ & 449 & 0.363 & 1007 & 81.8 & 24.6 & 10.1 & 0.412 \\
\hline & 561 & 0.444 & $E=55, R=50$ & 439 & 0.909 & 1000 & 204.7 & 24.3 & 15.5 & 0.636 \\
\hline & 581 & 0.444 & $E=85, R=5$ & 310 & 0.059 & 892 & 13.3 & 30.8 & 8.7 & 0.284 \\
\hline & 572 & 0.444 & $E=85, R=20$ & 304 & 0.235 & 876 & 52.9 & 29.1 & 10.7 & 0.369 \\
\hline & 569 & 0.444 & $E=85, R=50$ & 302 & 0.588 & 872 & 132.4 & 26.3 & 14.4 & 0.550 \\
\hline
\end{tabular}

$E, R$ elastic $\left(\mathrm{cmH}_{2} \mathrm{O} / \mathrm{L}\right)$ and resistive $\left(\mathrm{cmH}_{2} \mathrm{O} / \mathrm{L} / \mathrm{s}\right)$ loads, respec- constants, respectively. Measured data represent mean values of tively; $V_{T}$ tidal volume; $E_{E}, R_{E}$ effective elastance and resistance, three experimental determinations

respectively; $\tau_{\mathrm{F}}, \tau_{\mathrm{V}}$, and $\tau_{\mathrm{E}}$, fixed, variable, and effective time

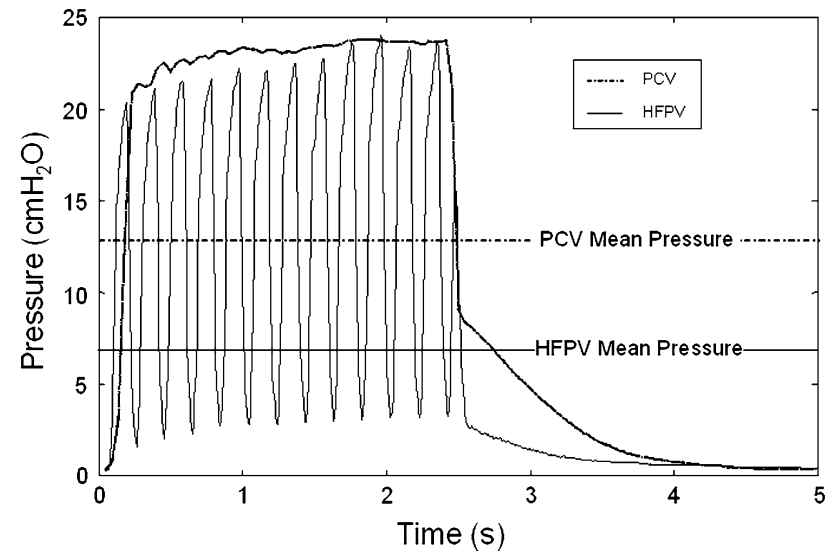

Fig. 1 Pressure-time curves obtained with high-frequency percussive ventilation (HFPV) and pressure-controlled ventilation (PCV) during one breathing cycle. Elastic and resistive loads applied to the variable branch of the model amounted to $35 \mathrm{cmH}_{2} \mathrm{O} / \mathrm{L}$ and $50 \mathrm{cmH}_{2} \mathrm{O} / \mathrm{L} / \mathrm{s}$, respectively; miniburst frequency equaled 300 cycles/min. Note that mean pressure generated by HFPV approximates $55 \%$ of that produced by PCV

Effect of elastance

A similar behavior characterized HFPV and PCV during elastic load variation. Descriptively, overall lung $V_{\mathrm{T}}$ diminished with increasing $E$ and was not appreciably affected by $R$. In the fixed branch, $V_{\mathrm{T}}$ augmented $<10 \%$ with increasing elastance applied to the variable branch of the model and did not vary with different $R$. On the other hand, the gas volume introduced into the variable branch decreased with increasing elastic loading (Tables 1,2).

\section{Effect of resistance}

During HFPV, for the same elastic load, the smaller the resistive load in the variable branch, the higher $V_{\mathrm{T}}$ in this compartment. In the fixed branch, $V_{\mathrm{T}}$ augmented $<5 \%$ with increasing resistance applied to the variable branch of the model (Table 1). In the overall lung during PCV, $V_{\mathrm{T}}$ diminished to a larger extent with the smallest resistive load. On the other hand, the gas volume introduced into the variable branch decreased with increasing $R$ (Table 2).

Effective mechanical constants

Effective elastances $\left(25.4 \pm 3.4\right.$ and $29.5 \pm 10.7 \mathrm{cmH}_{2} \mathrm{O} /$ L), resistances $\left(10.9 \pm 3.9\right.$ and $\left.9.4 \pm 4.5 \mathrm{cmH}_{2} \mathrm{O} / \mathrm{L} / \mathrm{s}\right)$, and time constants $(0.43 \pm 0.15$ and $0.37 \pm 0.22 \mathrm{~s})$ did not differ when comparing HFPV and PCV, respectively $(P=0.296,0.474$, and 0.520).

\section{Washout efficiency}

Table 1 presents the percentage of total cumulative pulsatile volume $\left(V_{\text {TOT }}\right)$ resulting in tidal volume $\left(V_{\mathrm{T}}\right), V_{\mathrm{T}} /$ $V_{\text {TOT }}$, measured in the overall lung model and in its variable and fixed branches as a function of resistive and elastic loading during HFPV. Both in the total system as in the two branches, $V_{\text {TOT }}$ did not change appreciably with $E$, whereas it fell with increasing $R$. For the same elastic load, the smaller the resistive load in the variable branch, the higher $V_{\mathrm{TOT}}$, but the smaller $V_{\text {TOT }}$ in the fixed branch (Table 1). In the total lung and its variable branch, the washout efficiency $\left(V_{\mathrm{TOT}} / V_{\mathrm{T}}\right)$ increased with increasing elastic loading and decreasing resistive loading (Table 1).

Trapped air volume

TAV and PEEPi in the face of different resistive and elastic loads determined during HFPV and PCV are depicted in ESM 3. 


\section{Discussion}

HFPV provides tidal volume as the difference between its pulsatile in- and out-volumes [20]. In all instances, some amount of gas is washed out of the lungs throughout inspiration. Characteristically the performance of the HFPV device varies according to the physiological/ physical feedback of the lung/model, i.e., with its impedance (or its resistive and/or elastic components) $[19,20]$. So far, some modeling of the interaction between HFPV and lung mechanical characteristics has been reported $[19,20]$, but to our knowledge no two-compartment model with unequal time constants has been tested. Furthermore, the results generated by HFPV were compared with those provided by PCV. Considerations on the bicompartmental lung model are included in ESM 4.

During HFPV, for the same elastic load, the smaller the resistive load in the variable branch, the higher $V_{\mathrm{TOT}}$ and $V_{\mathrm{T}}$ in this compartment, but the smaller $V_{\mathrm{TOT}}$ and $V_{\mathrm{T}}$ in the fixed branch. However, $V_{\mathrm{T}}$ changed to a much lesser extent than $V_{\text {TOT. }}$. The largest elastic load yielded the smallest $V_{\mathrm{T}}$ in the variable branch. $V_{\mathrm{T}}$ in the fixed branch was less affected by either resistive or elastic loading than the variable branch, as shown in Table $1 . V_{\mathrm{T}} /$ $V_{\text {TOT }}$ decreased with increasing elastance and decreasing resistance [20]. The same results were found in the present investigation (Table 1). Both the $R$ and $E$ dependence of $V_{\mathrm{T}} / V_{\mathrm{TOT}}$ are more important in the variable branch of the system (Table 1) than in the fixed one. In such a model, the measurement of $V_{\mathrm{T}} / V_{\mathrm{TOT}}$ at the entrance of the respiratory system may be misleading, since the values at this point can be closer to those found either in the fixed branch of the system or in the variable one, according to the applied elastic and resistive loads. Table 1 shows also that, in the total system and in its variable compartment, lung washout efficiency $\left(V_{\mathrm{TOT}} / V_{\mathrm{T}}\right)$ increased with increasing $E$ and decreasing $R$, while it increased with increasing $R$ and was not modified substantially by $E$ in the fixed compartment. Once again the behavior of the system cannot predict the outcomes in each compartment. These differences could be explained by the HFPV characteristics, different time constants in each pathway, and inertial forces.

Considering that the time constants in the two compartments are unequal, $E_{\mathrm{E}}, R_{\mathrm{E}}$, and $\tau_{\mathrm{E}}$ vary as a function of frequency [21]. Indeed, in our modeling, inspiratory flow oscillates at $300 \mathrm{cpm}$ during HFPV, whereas breathing frequency amounts to $12 \mathrm{bpm}$ under PCV. Under HFPV, $R_{\mathrm{E}}$ varied from 3.9 to $14.4 \mathrm{cmH}_{2} \mathrm{O} / \mathrm{L} / \mathrm{s}$ [21]; in this range tidal volume did not change appreciably in the previously reported one-compartment model in which resistance varied between 5 and $20 \mathrm{cmH}_{2} \mathrm{O} / \mathrm{L} / \mathrm{s}$ at similar elastance values [20]. On the other hand $E_{\mathrm{E}}$ varied from 19.5 to $54.1 \mathrm{cmH}_{2} \mathrm{O} / \mathrm{L}$; under these conditions tidal volume varied in the one-compartment model considering the same resistance range [20]. Under the present conditions, for the same loading, PCV generates higher $V_{\mathrm{T}}$ than HFPV (Tables 1,2). This finding reinforces the lung-protective behavior of the latter, which associates convective and diffusive ventilation to promote gas exchange. Additionally, the measurement of lumped parameters such as effective elastance, resistance, and time constant does not provide a clear picture of the mechanical heterogeneities occurring between distinct pulmonary compartments when HFPV and PCV are used, since no statistically significant difference was found between them.

$\mathrm{Paw}_{\mathrm{m}}$ during HFPV is smaller than that generated by PCV. Pressure-time curves obtained under both conditions are depicted. $\mathrm{Paw}_{\mathrm{m}}$ generated by HFPV approximates $55 \%$ of that produced by PCV (Fig. 1). It should be stressed that $V_{\mathrm{T}}$ in HFPV and PCV amounted to 0.68 (Table 1) and 1.09 L (Table 2), respectively, the ratio between them amounting to 0.62 , i.e., a value similar to that found for $\mathrm{Paw}_{\mathrm{m}}$. This finding supports the notion that HFPV possibly protects the lung, since $\mathrm{Paw}_{\mathrm{m}}$ is small but lung washout is preserved. Additionally, it should be mentioned that, if pressure changes during inspiration alone were considered, the relationship between $\mathrm{Paw}_{\mathrm{m}}$ and $V_{\mathrm{T}}$ in HFPV mode was identical to that in PCV. Owing to the intrinsic characteristics of each ventilator, after-end-inspiration pressure falls very quickly in HFPV, whereas under PCV there is a slower decrease in pressure, which contributes to the higher $\mathrm{Paw}_{\mathrm{m}}$ ratio observed during the overall breathing cycle.

As also found with HFPV, in PCV mode $V_{\mathrm{T}}$ fell with increasing $R$ and $E$, as discussed above and elsewhere [23-25]. The differences between the $V_{\mathrm{T}}$ values measured in the fixed and variable branches of the model are larger than those detected in HFPV (Tables 1,2). On the other hand, under PCV the absolute values in the fixed compartment were greater than those measured during HFPV, in line with the findings pertaining to $\mathrm{Paw}_{\mathrm{m}}$. Under PCV the ventilator does not adjust its output according to the model input impedance, and the gas distribution obeys more closely the model introduced by Otis et al. [21], as can be seen in Table 2 .

$V_{\text {TOT }}$ in HFPV was found to be always larger than tidal volume in PCV mode. Peak pressure, $I / E$ ratio, and respiratory frequency were similar in both conditions. It follows that, although tidal volume is smaller in HFPV, this ventilatory mode provides a continuous in and out gas movement that washes the lung out while maintaining it less inflated, as previously reported [20]. The capability to modulate lung inflation $\left(V_{\mathrm{T}}\right)$ and washout $\left(V_{\mathrm{TOT}}\right)$ at different elastic and resistive loadings is a distinctive and intrinsic characteristic of HFPV, evaluated by the $V_{\mathrm{TOT}} /$ $V_{\mathrm{T}}$ ratio (Table 1). In the face of small $E$ and large $R$, the time constant increases and the lung recoil decreases, thus yielding the smallest pulsatile volume in HFPV, since the 
high resistance slows down inspiration while the small elastance is not able to induce quick washout. On the other hand, a small $R$ allows a large inspiratory limb, and a high $E$ induces a quick expiratory limb [19, 20, 24, 25].

Peak airway pressure was very similar in both ventilatory patterns. However, as mentioned above, the volume injected that remained in the lung at end inspiration was smaller in HFPV (as well as $\mathrm{Paw}_{\mathrm{m}}$ ). Thus, in the presence of small resistances and elastances, the probability of air trapping would increase under both ventilatory patterns, but to a lesser extent in HFPV (ESM 3), even though both ventilatory modes present the same $\tau_{\mathrm{E}}$. Indeed TAV and PEEPi were significantly larger under PCV. A larger expired volume demands a longer $T_{\mathrm{E}}$ to be totally exhaled, and the smaller $V_{\mathrm{T}}$ values found during HFPV can by themselves explain the better outcome in terms of TAV and PEEPi.

Finally, considering the ratio between tidal volumes in the variable and fixed branches, $V_{\mathrm{T}, \mathrm{VAR}}$ and $V_{\mathrm{T}, \mathrm{FIX}}$ in PCV and HFPV modes, respectively, and the ratio between total volumes in the variable and fixed branches, $V_{\mathrm{TOT}}$, VAR and $V_{\text {TOT.FIX, }}$, respectively, in HFPV alone, we found significant relationships that link the former ratios with elastance and the latter ones with resistance by means of an iterative least-mean-square open-source $\mathrm{R}$ package routine [22]. The following equations resulted:

$$
\begin{gathered}
\frac{V_{\mathrm{T}, \mathrm{VAR}}}{V_{\mathrm{T}, \mathrm{FIX}}}=1.53-0.012 \times E \\
\left(P<0.001 ; R^{2}=0.91\right), \\
\frac{V_{\mathrm{T}, \mathrm{VAR}}}{V_{\mathrm{T}, \mathrm{FIX}}}=2.34-0.02 \times E \\
\left(P=0.001 ; R^{2}=0.81\right), \\
\frac{V_{\mathrm{TOT}, \mathrm{VAR}}}{V_{\mathrm{TOT}, \mathrm{FIX}}}=0.56+\frac{5.17}{R} \\
\left(P<0.001 ; R^{2}=0.95\right) .
\end{gathered}
$$

Equations 1 and 2 describe a linear decreasing relation between volume ratio and elastance, independently of resistance during PCV and HFPV, respectively. Equation 3 shows an inverse proportional relationship between total volumes ratio and resistance, independently of elastic loads.

In PCV, volume delivery is convective and its distribution mainly follows the elastic load variations. Our bicompartmental mechanical lung model is coherent with these findings because, for a theoretical $E$ value of $44 \mathrm{cmH}_{2} \mathrm{O} / \mathrm{L}$ in the variable branch compared with $45 \mathrm{cmH}_{2} \mathrm{O} / \mathrm{L}$ in the fixed one, the ratio between $V_{T, V A R}$ and $V_{\mathrm{T}, \mathrm{FIX}}$ is equal to 1 (Equation 1), i.e., the volume distribution is equivalent in the two branches. During HFPV, isovolumetric distribution occurs for a theoretical elastance value of $67 \mathrm{cmH}_{2} \mathrm{O} / \mathrm{L}$ in the variable branch compared with $45 \mathrm{cmH}_{2} \mathrm{O} / \mathrm{L}$ in the fixed one (Equation 2). This occurs because $V_{\mathrm{T}}$ accumulated into the branches is the result of $V_{\mathrm{TOT}}$, which is closely dependent on $R$ (Equation 3 ) as a consequence of a high-speed flow delivery. To explain this discrepancy it is necessary to consider the effective values of $E, R$, and $\tau$, which take into account the consequence of different frequencies applied during PCV and HFPV. As shown in Tables 1 and 2 , isovolumetric distribution between the fixed and variable compartments is obtained during HFPV and PCV, when the pathways are characterized by the same $\tau_{\mathrm{E}}$ (0.613 and 0.621 , respectively).

\section{Study limitations}

As previously described by Otis et al. [21], if separate branches of the model have different time constants, the flows will be out of phase with each other, so that they will not cross the zero line simultaneously, and at the points when flows are null, gas will pass between the independent branches in the common path (pendelluft), which we did not include in the calculations. Additionally, since the time constants in the two compartments were in most cases diverse, no simple model could approximate the mechanical characteristics of the system; the behavior of elastance and resistance would be frequency dependent. It should be stressed that a twocompartment model represents a major simplification of the real heterogeneous lung; therefore, generalization of the conclusions to clinical situations must be undertaken cautiously. We used 300 cycles/min because, so far, there is no proof that the volumes generated by the VDR-4 device are frequency independent. Moreover, it should be mentioned that the amplitude of the minibursts can be modified by the oscillatory frequency. Finally, our bench study results should be clinically considered bearing in mind the absence of volume alarms in VDR-4.

\section{Conclusions}

We have contributed information on the distribution of inspired volume according to resistive and elastic loads in a two-compartment nonuniform model of the lung. HFPV accommodated volume distribution without overinflating compartments with low time constants, thus presenting a potential beneficial behavior in mechanically heterogeneous lungs. The main advantage of HFPV seems to be ventilation at a lower mean airway pressure and lower inspiratory volumes, thus providing a protective effect against volutrauma and barotrauma. At the same time, oxygenation could be maintained by the association of convective and diffusive ventilation. Finally, the findings 
of this bench study suggest that comparison between HFPV and conventional ventilation in terms of supposed volume delivery should be carefully considered.
Acknowledgments Support was provided solely from institutional and/or departmental sources: University of Trieste, Cattinara Hospital, Trieste, Italy. W. A. Zin (Visiting Professor) was partially supported by FAPERJ, Brazil.

\section{References}

1. Salim A, Martin M (2005) Highfrequency percussive ventilation. Crit Care Med 33:s241-s245

2. Antonaglia V, Lucangelo U, Zin WA (2006) Intrapulmonary percussive ventilation improves the outcome of patients with acute exacerbation of chronic obstructive pulmonary disease using a helmet. Crit Care Med 34:2940-2945

3. Lentz W, Peterson HD (1996) Smoke inhalation is a multilevel insult to the pulmonary system. Curr Opin Crit Care 2:230-235

4. Loring WR III, Cioffi WG, Mason AD, McManus WF, Pruitt BA (1993) Improved survival of burned patients with inhalation injury. Arch Surg 128:772-780

5. Lucangelo U, Zin WA, Antonaglia V (2006) High-frequency percussive ventilation during surgical bronchial repair in a patient with one lung. Br $\mathbf{J}$ Anaesth 96:533-536

6. Reper P, Dankaert R, van Hille F, Van Laeke P, Duinslaeger L, Vanderkelen A (1998) The usefulness of combined high frequency percussive ventilation during acute respiratory failure after smoke inhalation. Burns 24:34-38

7. Reper P, Wibaux O, Van Laeke P, Vandeenen D, Duinslaeger L, Vanderkelen A (2002) High frequency percussive ventilation and conventional ventilation after smoke inhalation: a randomised study. Burns 28:503-508

8. Reper P, Van Bos R, Van Loey K, Van Laeke P, Vanderkelen A (2003) High frequency percussive ventilation in burn patients: hemodynamics and gas exchange. Burns 29:603-608

9. Rodeberg DA, Housinger A, Greenhalgh DG, Maschinot NE, Warden GD (1994) Improved ventilatory function in burn patients using volumetric diffuse respiration. J Am Coll Surg 179:518-522
10. Baird JS, Johnson JL, Escudero J, Powars DR (1994) Combined pressure control/high frequency ventilation in adult distress respiratory syndrome and sickle cell anemia. Chest 106:1913-1916

11. Campbell PJ, Chilton HW, Garvey PA, Gupta JM (1991) Volumetric diffuse respirator use in neonatal respiratory failure. J Paediatr Child Health 27:31-33

12. Allardet-Servent J, Bregeon F, Delpierre S, Steinberg JG, Payan MJ, Ravailhe S, Papazian L (2008) Highfrequency percussive ventilation attenuates lung injury in a rabbit model of gastric juice aspiration. Intensive Care Med 34:91-100

13. Barrette RR, Hurst JM, Branson RD, Davis K Jr (1987) A comparison of conventional mechanical hyperventilation with two forms of high frequency ventilation for the control of intracranial pressure in closed head injury. Respir Care 32:733-740

14. Hurst JM, Branson RD, De Haven CB (1987) The role of high frequency ventilation in post-traumatic respiratory insufficiency. J Trauma 27:236-241

15. Ranieri VM, Suter PM, Tortorella C, De Tullio R, Dayer JM, Brienza A, Bruno F, Slutsky AS (1999) Effect of mechanical ventilation on inflammatory mediators in patients with acute respiratory distress syndrome: a randomized controlled trial. JAMA 282:54-61

16. Ranieri VM, Giunta F, Suter PM, Slutsky AS (2000) Mechanical ventilation as a mediator of multisystem organ failure in acute respiratory distress syndrome. JAMA 284:43-44

17. Velmahos GC, Chan LS, Tatevossian R, Cornwell EE III, Dougherty WR, Escudero J, Demetriades D (1999) High frequency percussive ventilation improves oxygenation in patients with ARDS. Chest 116:440-446
18. Paulsen SM, Killyon GW, Barrillo DJ (2002) High frequency percussive ventilation as a salvage modality in adult respiratory distress syndrome: a preliminary study. Am Surg 68:852-856

19. Lucangelo U, Antonaglia V, Zin WA, Fontanesi L, Peratoner A, Bird FM, Gullo A (2004) Effects of mechanical load on flow, volume and pressure delivered by high-frequency percussive ventilation. Respir Physiol Neurobiol 142:81-91

20. Lucangelo U, Antonaglia V, Zin WA, Berlot G, Fontanesi L, Peratoner A, Bernabè F, Gullo A (2006) Mechanical loads modulate tidal volume and lung washout during high-frequency percussive ventilation. Respir Physiol Neurobiol 150:44-51

21. Otis AB, McKerrow CB, Bartlett RA, Mead J, McIlroy MB, Selverstone NJ, Radford EP (1956) Mechanical factors in distribution of pulmonary ventilation. J Appl Physiol 8:427-443

22. R Development Core Team (2006) R: A language and environment for statistical computing. R Foundation for Statistical Computing, Vienna, Austria.

http://www.R-project.org. Accessed 06 Jan 2006

23. Milic-Emili J, Zin WA (1986) Breathing responses to imposed mechanical loads. In: Cherniack NS, Widdicombe JG (eds) Handbook of physiology. Section 2 . The respiratory system: control of breathing, vol 2, part 2. American Physiological Society, Bethesda, pp 751-769

24. Zin WA, Rossi A, Zocchi L, MilicEmili J (1984) Model analysis of tidal volume response to inspiratory elastic loads. J Appl Physiol 57:271-277

25. Zin WA, Rossi A, Milic-Emili J (1983) Model analysis of respiratory responses to inspiratory resistive loads. J Appl Physiol 55:1565-1573 